\title{
REVISTAMARACANAN
}

Dossiê

\section{República de Weimar, suas crises e o Nazismo como alternativa}

\section{The Weimar Republic, its crises and the emergence of Nazism as an alternative}

\author{
Luís Edmundo de Souza Moraes \\ Universidade Federal Rural do Rio de Janeiro \\ luisedmundomoraes@gmail.com
}

\begin{abstract}
Resumo: O propósito deste artigo é o de refletir sobre as variáveis que permitem pensar sobre o fim da República de Weimar e sobre o crescimento do Partido Nazista na Alemanha de princípios da década de 1930. A expectativa é a de, por meio da sistematização de conhecimentos consolidados na literatura especializada, considerar o peso da crise generalizada que atinge a Alemanha a partir do inverno de 1929-1930 como fator explicativo para a derrota do projeto republicano liberal e para a emergência do nazismo como alternativa política naquele contexto específico.
\end{abstract}

Palavras-Chave: Alemanha; República de Weimar; Nazismo; Crise.

Abstract: The purpose of this article is to consider the variables that allow us to assess the end of the Weimar Republic and the growth of the Nazi Party in Germany in the early 1930s. It is expected that, through the systematization of consolidated knowledge on the subject, we are able to consider the role played by the generalized crisis that reaches Germany in the winter of 1929-1930 as an explanatory factor for the defeat of the liberal republican project and for the emergence of Nazism as a political alternative in that specific context.

Keywords: Germany; Weimar Republic; Nazism; Crisis.

Recebido: Novembro 2017

Aprovado: Dezembro 2017 


\section{Introdução}

O colapso da República de Weimar está entre os fenômenos políticos do século XX que mais intensamente mobilizou cientistas sociais. Não há dúvida de que parte deste apelo tem relação com o fato de que essa primeira experiência democrático-liberal na Alemanha foi sucedida pela ditadura nazista.

E em função de seu futuro, a República de Weimar chamou a atenção de muitos que se confrontaram com a tarefa de dar algum sentido para a chegada de Hitler ao cargo de primeiroministro da Alemanha em 30 de janeiro de 1933.

Do ponto de vista da história escrita pelos nazistas, essa conquista foi exclusivamente o resultado da luta travada por Hitler e por seu movimento para alcançar este objetivo. Esta ideia, presente em toda a historiografia nazista, foi expressa de modo paradigmático no título do filme dirigido por Leni Riefenstahl: "O Triunfo da Vontade". ${ }^{1}$

Ironicamente, o sociólogo Paul Massing, escrevendo sob o pseudônimo de Karl Billinger, comenta:

Os historiadores nazistas têm tido uma vida fácil. Eles não têm mais problemas para resolver. [...] Eles têm que apresentar a história alemã como a história dos grandes alemães apenas. O maior alemão chegou ao poder pelo próprio fato de que ele é maior, mais enérgico e mais perspicaz do que qualquer um de seus oponentes, porque ele lutou com as armas certas e porque ele seguiu com a segurança de um sonâmbulo a estrada que a providência indicou para ele. ${ }^{2}$

Ainda assim, este foi um motivo que, mesmo que apresentado de forma não tão caricata, teve vida relativamente longa no pós-guerra: Hitler deveria ser pensado como a chave para a compreensão do fenômeno, de seus caminhos e descaminhos.

Distanciando-se dessa perspectiva, os anos trinta e quarenta veem emergir uma tese que toma o nazismo como uma emanação da "alma" alemã ou, na melhor das hipóteses, das profundezas da história alemã. Esta tese adquiriu diversas faces, algumas mais outras menos sofisticadas, mas todas remetendo a uma essência dos alemães que os conduziu ao nazismo. ${ }^{3 .}$

Um conjunto grande de trabalhos, reagindo tanto ao essencialismo desta última, quanto ao

\footnotetext{
${ }^{1}$ Para exemplos de como a historiografia nazista lida com o tema, Cf.: SUCHENWIRTH, Richard. Deutsche Geschichte. Leipzig: Verlag von Gerorg Dollheimer, 1935; e, BOUHLER, Philipp. Adolf Hitler: Das Werden einer Volksbewegung. Lübeck: Verlag von Charles Coleman, 1941.

2 BILLINGER, Karl. Hitler is no Fool: The menace of the man and his program. Nova York: Modern Age Books, 1939 , p. 88.

3 Um dos primeiros trabalhos que expressam esta virada de ênfase no olhar foi o livro de Gerhart Eisler, Albert Norden e Albert Schreiner (The Lesson of Germany: a Guide her History. New York: International Publishers, 1945), que volta ao movimento de reforma religiosa de Martinho Lutero para explicar o nazismo. Variações deste mesmo motivo se encontram, entre outros em SHIRER, William L. Ascensão e Queda do Terceiro Reich. Rio de Janeiro, Editora Civilização Brasileira, 1964. 4 vols. cf., em especial, vol. 1, cap. 4.
} 
personalismo da primeira, chamou a atenção para variáveis de uma conjuntura muito particular: os nazistas chegaram ao poder no contexto de uma longa crise econômica que foi agudizada pela quebra da bolsa de Nova York em Outubro de 1929.

Alguns trabalhos radicalizaram esta atenção para o contexto de depressão econômica e acabaram por associar, de forma direta, a crise econômica e social e o crescimento do nazismo. E os dados parecem sugerir exatamente isto:

Tabela 1 - Relação entre Taxa de Desemprego e votação no NSDAP (em \%) ${ }^{4}$

\begin{tabular}{|c|c|c|}
\hline & Taxa de Desemprego & Votos no NSDAP \\
\hline Set. 1930 & 18,3 & 14,1 \\
\hline Jul. 1932 & 29.7 & 37,3 \\
\hline Nov. 1932 & 28,3 & 33,1 \\
\hline Mar. 1933 & 34.3 & 43,9 \\
\hline
\end{tabular}

A relação parece, de fato, ser direta: o movimento dos votos no NSDAP acompanha o crescimento e o decréscimo da taxa de desemprego na Alemanha, fazendo com que as consequências da crise tenham sido consideradas como suficientes para explicar o voto no NSDAP e a sua chegada ao poder na Alemanha em $1933 .^{5}$

Comum a essas abordagens é a percepção de que se pode dar conta do fim da República de Weimar e do estabelecimento da ditadura nazista por meio de explicações fundadas em uma única variável.

Em contraposição a isto, progressivamente se afirmou a ideia de que estes fenômenos não se permitiam ser tão facilmente explicados. Nem mesmo a correspondência, aparentemente direta e inequívoca entre o crescimento do desemprego e o crescimento do voto nos nazistas se mostrou tão simples depois de análises mais sofisticadas sobre comportamento eleitoral e a variação regional de votos para os diversos partidos que disputavam a preferência do eleitorado. ${ }^{6}$

Com isto, especificamente em relação ao problema da crise como fator explicativo para esses fenômenos, na historiografia se afirmou com sucesso a posição que considera que, se não

\footnotetext{
${ }^{4}$ Tabela composta a partir dos dados apresentados por: FREY, Bruno S. Economics As a Science of Human Behaviour Towards a New Social Science Paradigm. New York: Springer Science \& Business Media, 1992, p. 54.

5 Para matizes distintos desta posição, cf.: KALTEFLEITER, Werner. Wirtschaft und Politik in Deutschland Konjunktur als Bestimmungsfaktor des Parteiensystems. Wiesbaden: Springer Fachmedien, 1968 especialmente o cap. 2: Wirtschaft und Politik in der Weimarer Republik -; BORCHARDT, Knut. Perspectives on modern German economic history and policy. Cambridge: Cambridge University Press, 1991 especialmente o cap. 10: Economic causes of the collapse of the Weimar Republic -; e, FREY, Bruno S. Economics As a... Op. cit. - especialmente o cap. 4: Politics: Unemployment and National Socialism.

${ }^{6}$ Cf., por exemplo: FALTER, Jürgen. Unemployment and the Radicalisation of the German Electorate 19281933: An Aggregate Data Analysis with Special Emphasis on the Rise of National Socialism. In: STACHURA, Peter D. (org.). Unemployment and the Great Depression in Weimar Germany. New York: Palgrave, 2001.
} 
há dúvida de que a crise de 1929 teve um papel importante como impulsionadora do aumento do apelo popular do nazismo, ela está longe de ser suficiente para explicar o fim da República de Weimar e o estabelecimento da ditadura nazista.

Ao refletir sobre o impacto da crise de princípios da década de 1930 na ascensão do nazismo, este artigo se propõe apresentar estas variáveis que se afirmaram na historiografia como ponto de partida largamente partilhado para refletir sobre o fim da república de Weimar e o estabelecimento da ditadura nazista. O que segue, assim, busca sistematizar o conhecimento disponível sobre as variáveis que permitem avaliar o peso da crise generalizada para entender tanto a derrota do projeto republicano liberal quanto o fato de que ele foi substituído pelos nazistas e não por algum outro grupo político.

\section{Um voo sobre a República de Weimar}

\subsection{Partidos, Eleições e Governos}

A República de Weimar é considerada como o período da história alemã que se segue à queda da monarquia e à proclamação da República pelo social-democrata Philipp Scheideman (09/11/1918) e que antecede a chegada de Hitler à função de primeiro-ministro (Chanceler) da Alemanha (30/01/1933). Ela foi uma república democrática liberal, fundada em um sistema parlamentarista, com representação proporcional e sem cláusula de barreira.

Os governos (Gabinetes) eram formados ou por meio de maiorias parlamentares fundadas em alianças partidárias (governo de maioria) ou, caso uma maioria parlamentar não pudesse ser constituída, pela "tolerância" da maioria dos parlamentares, significando isto a concordância da maioria de não recusar o governo indicado ou mesmo de votar por sua dissolução.

Uma variável importante do parlamentarismo de Weimar diz respeito ao lugar do Presidente da República nesse sistema: era dele a iniciativa de indicar a formação de um governo e de apontar o primeiro-ministro e ele tinha a possibilidade de dissolver o parlamento e convocar novas eleições. Em situações de emergência, o presidente poderia ainda suspender temporariamente direitos civis e governar por decreto, fator decisivo para a dissolução da república.

Em seus processos eleitorais tomavam parte partidos nacionais, partidos locais, ou listas eleitorais formadas por grupos de interesse, não raro, formadas para disputar uma única eleição e com existência efêmera.

Os grandes partidos ou aqueles de representação mais estável no parlamento foram o Partido Social-Democrata da Alemanha (SPD, socialista), o Partido Comunista da Alemanha (KPD), o Partido do Centro (Zentrumspartei ou simplesmente Zentrum, um partido católico) e seu 
correspondente na Baviera, o Partido Popular Bávaro (BVP), o liberal Partido Democrático Alemão (DDP, renomeado em 1930 para Deutsche Staatspartei - DStP), o Partido Popular (DVP, nacionalista) e o conservador Partido Popular Nacional-Alemão (DNVP, Nacional-alemão) ${ }^{7}$.

Estes partidos têm sido classificados e agrupados de formas diferentes pela literatura sobre o tema. É frequente o seu ordenamento considerando a adesão programática de membros e eleitores, fazendo com que eles conformem três grupos: a esquerda (social-democratas e comunistas de matizes distintos), o campo Católico (o Zentrum e o Partido Popular Bávaro) e o campo Burguês-Protestante (na realidade um classificador negativo por que reunia todos os partidos que não eram de esquerda ou católicos) ${ }^{8}$

Mas, ao considerarmos a relação dos partidos com a República de Weimar, podemos fazer um ordenamento distinto dos partidos:

Por um lado, o campo republicano é formado em torno dos três partidos que dão sustentação ao projeto weimariano: o Partido Social-Democrata Alemão, fundador e único defensor permanente do projeto de uma república parlamentar liberal-democrática, o Partido do Centro e o Partido Democrático Alemão (DDP), chamados por seus inimigos da república de Sistemparteien, partidos do sistema de Weimar.

Por outro lado, o antirrepublicanismo se fazia representar institucionalmente, à esquerda, por grupos comunistas de pouca expressividade e, à direita, por organizações que iam de partidos marcadamente identificados com a monarquia como Partido Popular Nacional-Alemão, a grupos militarizados de extrema direita como a influente organização de ex-combatentes Stahlhelm (os capacetes de aço), e um leque grande de partidos de extrema direita como o Partido da Liberdade Völkisch-Alemã (Deutschvölkische Freiheitspartei - DVFP) e o Partido Nacional Socialista dos Trabalhadores Alemães (Nationalsozialistische Deutsche Arbeiterpartei - NSDAP), o partido nazista. A boa parte dos grupos e partidos völkisch são absorvidos pelo NSDAP até 1933.

Além disso, esta linha de demarcação atravessa também partidos de esquerda e de direita, nos quais tanto defensores quanto detratores da república encontram abrigo. Neste caso, estão o Partido Comunista Alemão e Partido Popular Alemão. O KPD, apesar da linha majoritária de luta contra a social-democracia e o projeto weimariano, possuía defensores de uma aliança de esquerda na defesa da república contra a extrema direita. Esta posição se consolida em um grupo de oposição denominado Kommunistische Partei-Opposition - KPO que rompe com o KPD em 1929. Da mesma forma, o DVP votara contra a constituição aprovada em 1919, mas participa das

7 É importante notar que o termo Nacional-Alemão está em itálico por se tratar de um campo político chamado Deutschnationale, que é uma tendência política nacionalista ultraconservadora e de extrema direita do cenário político alemão que possui expressão institucional em diversas associações e partidos dentre os quais na Liga Pan-Germânica e no Deutschnationale Volkspartei (DNVP).

${ }^{8}$ A este respeito, cf.: FALTER, Jürgen W. Wahlen und Wählerverhalten unter besondeer Berucksichtingue des Aufstiegs der NSDAP nach 1928. In: BRACHER, Karl Dietrich; FUNKE, Manfred \& JACOBSEN, Hans Adolf (orgs.). Die Weimarer Republik, 1918-1933: Politik, Wirtschaft, Gesellschaft. Düsseldorf: Droste, 1987, p. 484-485. 
coalizões republicanas entre 1920 e 1931. O partido, mesmo tendo sido um dos mais importantes sustentáculos da república, possui em suas fileiras adversários declarados do projeto weimariano como o grande industrial Hugo Stinnes, defensor da aproximação do DVP com o partido nazista. No final da república parte de seus quadros migra para o NSDAP. ${ }^{9}$

Indo da esquerda à direita, as forças políticas representadas no parlamento são partidos programáticos e possuem feições relativamente estáveis, mantendo identidade programática, ainda que, em função do jogo parlamentar, existam momentos em que partidos ou blocos de partidos reforçam uma tendência mais à esquerda ou mais à direita, alterando as configurações de alianças e de constituição de blocos.

O movimento eleitoral ao longo dos 14 anos indica uma grande estabilidade do percentual de votos (e de mandatos) nos campos da esquerda e dos partidos católicos e uma variação grande no campo burguês-protestante. Para este último, a história da república foi uma história de queda progressiva e estável de eleitores de partidos liberais, de crescimento do conservadorismo político e, mais marcadamente, de mudança de perfil das bancadas conservadoras, que no final da república eram claramente de extrema direita.

\subsection{A paisagem política}

Mas a política na República de Weimar em muito supera o terreno próprio a partidos, eleições, parlamentos e ao Estado.

Por maiores as mudanças, um dos elementos relativamente estável nos 14 anos de existência da República de Weimar é a configuração de campos políticos nos quais se articulam grupos maiores ou menores, institucionalizados ou não, que disputavam projetos de futuro para a Alemanha.

A primeira dessas divisões de campos é a que separa direita e esquerda, colocando de um lado do espectro político agrupamentos ou partidos socialistas, comunistas e anarquistas e, de outro, organizações Völkisch ${ }^{10}$, Monarquistas, Nacionais-alemães e conservadores. A eficácia social desta fronteira é inegável: por ela são constituídos ambientes sociais, redes de solidariedade e vínculos políticos entre grupos, partidos e indivíduos que se reconhecem como parte de um ou de outro destes campos e que são mais ou menos estáveis ao longo da história da república.

9 Sobre os comunistas, cf.: FLECHTHEIM, Ossip K. Die KPD in der Weimarer Republik. Hamburg: Junius Verlag, 1986. Sobre o DNVP e o DVP, cf.: FEUCHTWANGER, E.J. From Weimar to Hitler: Germany, 19181933. London: Macmillan, 1995.

${ }^{10} \mathrm{O}$ adjetivo völkisch é uma palavra cujas traduções mais frequentes em geral a esvaziam de seu sentido. Normalmente traduzida por "popular" (em casos extremos até mesmo "populista"!) o termo refere-se, antes, a um tipo de projeto político nacionalista de extrema direita assentado sobre o pensamento racista. Não é raro que quando se opta por não utilizar o original em alemão, o termo seja traduzido por "racista" em outras línguas europeias. 
Os campos Völkish e Nacional-Alemão possuíam interseções diversas, em especial em organizações formalmente suprapartidárias como Vereine für das Deutschtum im Ausland (VDA Sociedade para [o apoio aos] Alemães no Exterior). A VDA foi uma das mais importantes organizações de massa da República de Weimar, reunindo mais de 2 milhões de membros em milhares de grupos locais espalhados por toda a Alemanha e no Exterior e com uma agenda política adequada ao nacionalismo excludente e racista. ${ }^{11}$

Ainda assim, não se pode deixar de enfatizar que estes "campos" não são em nada homogêneos, existindo fronteiras internas separando em vários momentos decisivos socialistas e comunistas pela esquerda, ou nacionalistas Völkish e conservadores e monarquistas, pela direita.

Para além desta dimensão, um outro elemento da paisagem política da republica de Weimar são as formações militares ou paramilitares de esquerda e de direita e que são responsáveis pela militarização crescente da vida pública: Na extrema direita, que sempre combateu tanto a república como a democracia liberal, estão os grupos que começaram a ser formados ainda em 1918 por militares desmobilizados, os Corpos Francos (Freikorps), as associações nacionais de ex-combatentes, associações de exercício militar. De destaque no período foi o Stahlhelm, Bund der Frontsoldaten (Liga de Combatentes), organização paramilitar que foi fundada como uma organização de ex-combatentes sem vinculação partidária, ainda que se aproximasse do perfil de organizações da direita nacional-alemã e völkish, pelo tipo de nacionalismo excludente e por seu antissemitismo (ex-combatentes judeus, a partir de 1924, não foram mais aceitos como membros). Ao longo dos anos 20 o Stahlhelm se torna um dos bastiões da agitação antirrepublicana e antidemocrática na Alemanha e estende muito seu campo de atuações e sua composição. Em concordância com o exército, o Stahlhelm passou a oferecer treinamento militar para jovens adultos e a atuar em aliança com partidos do campo NacionalAlemão e Völkish, tendo estado envolvido em campanhas antirrepublicanas e passou a compor uma frente política com os nazistas e o DNVP em 1931. Em 1932, com apoio do DNVP, apresentou-se com candidato próprio à Presidência da República (Theodor Duesterberg) Em princípios da década de 1930, contava com 500.000 pessoas organizadas em suas fileiras. ${ }^{12}$

Compõe este universo, ainda, os muitos clubes-de-tiro espalhados pelo país, cujos membros tinham um perfil político próximo aos campos Nacional-Alemão e Völkisch e somavam cerca de 40.000 pessoas em meados da década de 1920. Além destes, existem ainda as milícias partidárias, como a Tropas de Assalto (Sturmabteilung - SA) do Partido Nazista, a organização do SPD chamada "Bandeira Preta-Vermelha-Dourada" (Reichsbanner Schwarz-Rot-Gold), e a "Liga Vermelha de Combatentes" (Rote Frontkämpferbund), do Partido Comunista Alemão. ${ }^{13}$

Ao lado das organizações paramilitares, a paisagem política da República de Weimar , um

${ }^{11}$ Sobre a VDA, cf.: VON GOLDENDACH, Walter \& MINOW, Hans-Rüdiger. Deutschtum Erwache: aus dem Innenleben des staatlichen Pangermanismus. Berlim: Dietz Verlag, 1994, cap. 2.

12 Sobre o Stahlhelm, cf.: FEUCHTWANGER, E. J. From Weimar to Hitler... Op. cit., p. 198-200.

${ }^{13}$ Cf.: RICHARD, Lionel. A República de Weimar. São Paulo: Companhia das Letras, 1988, p. 131-142. 
conjunto de instituições que fogem a um enquadramento partidário imediato, envolvendo pelo menos 530 jornais e perto de 550 associações, clubes políticos e grupos de pressão espalhados pelo país, além de intelectuais e personalidades que compõe a assim chamada "Revolução Conservadora de Weimar", a denominação dada um campo político de extrema direita que sem qualquer unidade institucional, partilhavam de ideias e programas comuns. ${ }^{14}$

Isto sugere que a abordagem do ambiente político no qual o partido nazista se afirma não deva se limitar à dimensão institucional da política. A penetração social de elementos programáticos da extrema direita no tecido social alemão não é, de fato, mensurável exclusivamente pelo desempenho eleitoral dos partidos de extrema direita. Decisivo aqui parece ser o fato de que elementos centrais da visão de mundo e do programa nazista circulam cotidianamente no espaço público por serem partilhadas por outras forças políticas e estão diariamente presentes em espaços sociais supostamente não políticos. Na realidade, temas caros à extrema direita como o antissemitismo, o nacionalismo exclusivista e racista e o anticomunismo foram fincando raízes para além das fronteiras políticas e sociais da extrema direita e tiveram uma abrangência muito maior do que o desempenho em disputas eleitorais faz crer.

Dessa forma, pensar no acolhimento eleitoral do Partido Nazista implica em não perder de vista que o ambiente político e ideológico da República de Weimar fez dos nazistas porta-vozes de ideias, valores e projetos políticos socialmente disseminados e que foram se consolidando (por que circulavam já há muito tempo) e se tornando socialmente legítimos por meio de grupos mais ou menos organizados e por instituições que não eram imediatamente reconhecidas como instituições do mundo da política, como os partidos o são. Espaços culturais, religiosos, esportivos também meios sociais onde essas ideias e valores eram reproduzidos e incorporados por um número de atores e de instituições que em muito superava o número de militantes organizados no partido nazista. ${ }^{15}$

\section{A República de Weimar e suas Crises}

\subsection{O Nascimento em meio a crise}

A República de Weimar é em geral periodizada tendo por base o par crise-estabilidade. Assim, ela é dividida em dois períodos de crise (1919-1924 e 1929-1933) e um período

\footnotetext{
${ }^{14}$ A este respeito, cf.: o estudo já clássico de SONTHEIMER, Kurt. Antidemokratisches Denken in der Weimarer Republik. Munique: Nymphenburger Verlag, 1968; WOODS, Roger. The Conservative Revolution in the Weimar Republic. London: Palgrave Macmillan, 1996; e, HERF, Jeffrey. O Modernismo Reacionário: Tecnologia, cultura e política na Republica de Weimar e no Terceiro Reich. São Paulo: Ensaio; Campinas: Ed. da Unicamp, 1993.

${ }^{15}$ A este respeito, cf.: PEUKERT, Detlev. The Weimar Republic: The crisis of classical modernity. London: Penguin Books, 1991, cap. 7.
} 
intermediário de estabilidade (1924-1929).

O primeiro período é marcado pelo estabelecimento de uma república democrático-liberal em meio a uma Guerra Civil e pelos efeitos do Tratado de Paz de Versailles para a Alemanha.

A "negociação da paz" foi um processo do qual os derrotados não puderam participar. 0 tratado que se propunha a construir uma paz definitiva para a Europa, foi estabelecido pelos aliados na conferência de Versailles reunida a partir de 18 de Janeiro de 1919 sem a presença da delegação alemã. Apesar da possibilidade formal de os alemães apresentarem emendas, quase todas as propostas alternativas e mediadoras foram recusadas. Na prática isto representou que o documento final, recebido pela delegação alemã em 16 de Junho, deveria ser aceito ou recusado em sua integralidade, sem qualquer possibilidade de negociação. Para aumentar a pressão, tropas francesas são deslocadas para a fronteira com a Alemanha, que seria invadida em caso de recusa.

A marca mais profunda deixada por Versailles foi gerada por aquilo que ficou conhecido como "a questão da culpa" (Die Schuldfrage). Por meio do artigo 231 os aliados declaram e obrigam a Alemanha a reconhecer que recaía exclusivamente sobre ela a responsabilidade pelo conflito e pela destruição e perda de vidas por ela provocadas.

O tratado faria a Alemanha perder um sétimo de seu território $\left(70.579 \mathrm{~km}^{2}\right), 10 \%$ de sua população (em torno de 6,5 Milhões de habitantes), metade do minério de ferro, um quarto do carvão mineral além de áreas importantes de produção agrícola. Além disso, a Alemanha perdia todas as colônias no ultramar, deveria entregar parte de seus navios e locomotivas e ainda se obrigava a pagar 132 bilhões de marcos-ouro (pouco mais de dois bilhões anuais, mais juros e amortizações) e entregar anualmente doze por cento do valor das exportações. O tratado estabelecia ainda zonas desmilitarizadas ao longo das fronteiras (interferindo no princípio de soberania). ${ }^{16}$

Contra estas condições, protestos em massa têm lugar na Alemanha, onde é unânime a percepção de que o país está sujeito à arbitrariedade dos vencedores. Tão logo foi assinado, sua revisão se tornou o primeiro objetivo da política externa da República de Weimar durante toda a sua existência. Paralelamente, o Tratado se torna uma arma eficaz no processo de deslegitimação progressiva do regime republicano e das forças políticas que o sustentavam. Ele se torna, assim, combustível para a agitação antidemocrática e um elemento decisivo no processo de deslegitimação da República e da social-democracia, associada ao longo dos 14 anos da república à ideia de traição à nação pela assinatura do Diktat e por ter sido responsável pela derrota dos exércitos alemães na Guerra. ${ }^{17}$

${ }^{16}$ A respeito do Tradado e da questão das reparações, cf.: HAFFNER, Sebastian et al. Der Vertrag Von Versailles. Frankfurt a.M./Berlim: Ullstein, 1988.

17 Trata-se aqui do chamado "Mito da Punhalada pelas Costas" (die Dolchstosslegende). Este é um tema político de grande alcance quando se tem em vista o processo de deslegitimação das forças que sustentam a primeira república alemã. Trata-se de uma teoria conspiratória elaborada e propagada inicialmente pelo próprio Alto Comando do Exército Responsável direto pela construção e propagação do mito antirrepublicano foi o ex-chefe do Estado Maior do Comando Geral do Exército, o General Erich Ludendorf, que até meados 
Além de ser um peso político de grande alcance, o Tratado de Versailles provocou de forma direta uma aguda crise econômica. O pagamento das reparações e a fragilização da economia alemã daí decorrente fez com que a inflação, constante na república, tenha dado sinais de descontrole, com uma drástica desvalorização do Marco.

Em 11 de Janeiro de 1923, tropas franco-belgas ocuparam a Renânia e o Ruhr, regiões industriais e de produção de carbono, depois do governo francês ter acusado a Alemanha de, propositalmente, não pagar as indenizações. Ante a essa situação, o Governo do primeiro-ministro Wilhelm Cuno interrompe todos os pagamentos a franceses e belgas e dá início à chamada resistência passiva: de Berlim veio a diretiva para que os funcionários não obedecessem as ordens das forças de ocupação e é declarada uma greve geral na região. Grupos militarizados de extrema direita se organizam e praticam atos de sabotagem.

A ocupação da região do Ruhr produz uma queda significativa da receita do estado ao lado do aumento significativo de gastos para a sustentação da "resistência passiva", que chegou a custar algo como 30 milhões de marcos-ouro por dia. A desvalorização da moeda é tão rápida e tão grande que o câmbio pula de quase 18.000 marcos por dólar, em janeiro de 1923 para a impressionante cifra de mais de 4 trilhões de marcos por dólar em novembro.

Por outro lado, a invasão franco-belga e a política de resistência passiva produzem um grau de unidade ainda inédito na Alemanha do pós-guerra, reunindo em um mesmo esforço desde a extrema esquerda a grupos de extrema direita. ${ }^{18}$ Contudo, mesmo com este reposicionamento conjuntural das forças políticas em apoio ao governo republicano em função da ocupação do Ruhr, a crise econômica e social vai se tornar uma marca negativa perene na imagem da república, mantendo-se mesmo depois da recuperação econômica e de uma relativa estabilidade política que começa a desenhar-se em finais de 1923.

\subsection{A Estabilidade Ilusória}

As medidas iniciais para reverter o quadro de crise aguda e hiperinflação incluíram uma reforma monetária e a negociação, em agosto de 1924, de um plano que permitisse que a

dos anos 20 seria a pessoa de maior proeminência da extrema direita na Alemanha, curiosamente um dos envolvidos no esforço de persuadir o Imperador a buscar o armistício em função de derrotas decisivas sofridas pelo exército na frente de batalha. Segundo este mito, a Alemanha não havia sido derrotada no campo de batalha e os militares teriam tido todas as condições de levar o país à vitória não fosse pela traição de setores civis da política alemã, nomeadamente a social-democracia, a esquerda liberal e os judeus, que não teriam dado ao exército as condições de continuar a luta até a vitória, fazendo uma revolução doméstica contra a nação e o império e abrindo um período de caos político e social.

18 Os nazistas, ao que parece de forma isolada, assumiram posição contrária à ("desonrosa" e "vergonhosa") resistência passiva, que consideraram mais um ato de traição à nação por parte da coalizão de Weimar e fizeram um chamamento a uma "resistência ativa" de um outro tipo: "A palavra de ordem, disse Hitler em um discurso em princípios do ano, não deve ser 'abaixo a França', mas abaixo os traidores da pátria, abaixo os criminosos de novembro." Citado de acordo com: MASER, Werner. Der Sturm auf die Republik: Frügeschichte der NSDAP. Frankfurt/M. E Berlim: Ullstein, 1981, p. 368. 
Alemanha pagasse as reparações e recuperasse suas finanças e sua economia. O Plano Dawes teve o objetivo de reabilitar a moeda, reaquecer a economia e garantir o pagamento das reparações por meio de empréstimos externos (de curto prazo e vindos fundamentalmente dos Estados Unidos). Além disso, revendo parcialmente determinações do Tratado de Versailles, o pagamento de reparações foi submetido à capacidade econômica da Alemanha. ${ }^{19}$

Os efeitos econômicos e políticos dessas iniciativas, tanto no cenário internacional, quanto no doméstico, foram positivos e em um prazo curto, a economia dava sinais de recuperação e as tensões sociais diminuíam. As reações negativas ao Plano Dawes foram bastante reduzidas e limitadas aos comunistas e à extrema direita völkisch. Até mesmo a direita antirrepublicana freiou seus ataques à coalizão.

Ainda assim, foi pequeno o impacto da já sensível estabilização do país nas duas eleições de 1924 (maio e dezembro). Em maio, somente o Zentrum não experimentou perdas significativas. Em Dezembro o quadro se altera um pouco, com um crescimento pequeno do DDP e do DVP, e uma retomada mais significativa do SPD, mas que não encobriu o avanço do KPD, que quadruplicou sua representação, e de forças antirrepublicanas de direita: o DNVP com 95 cadeiras em maio e 103 em Dezembro e uma coalizão de grupos völkisch, no qual estava o NSDAP, com 32 cadeiras em maio e 14 em Dezembro.

Essa tendência se mostra ainda mais visível em 1925 nas eleições para Presidente da República, convocadas devido à morte do Social-Democrata, Friedrich Ebert. Três candidatos foram para um segundo turno: Wilhelm Marx, candidato da Coalizão de Weimar (SPD, DDP, Zentrum) Paul von Hindenburg, general, último chefe do comando supremo do exército, monarquista e candidato do campo antirrepublicano, e Ernst Thälmann, do Partido Comunista Alemão. Hindenburg, com 48,5\% dos votos, foi vitorioso, seguido por Marx $(45,2 \%)$ e Thälmann $(6,3 \%)$.

A eleição de um presidente antirrepublicano coincide com a radicalização de uma tendência à direita dos partidos liberal e de centro-direita (DDP, Zentrum, DVP), e à extrema direita völkisch do partido Nacional-Alemão (DNVP), todos eles cada vez menos dispostos a compor maioria parlamentar com o partido social democrata.

As eleições de 1928 pareceram fazer um freio a esta tendência. Foram justamente estes partidos os que sofreram as maiores perdas nestas eleições: das 264 cadeiras conquistadas em 1924, estes partidos só conquistaram 179 mandatos em 1928. A derrota do Bloco Burguês viu o crescimento dos social-democratas e dos comunistas (que pularam de 176 para 207 cadeiras em conjunto), fazendo com que a social-democracia, com seus 153 mandatos conquistados voltasse a entrar no cálculo político destes e fosse praticamente incontornável para a composição de um governo. Daí derivou a "Grande Coalizão" tendo à frente o social-democrata Hermann Müller, que

19 Sobre o plano Dawes, cf.: MOMMSEN, Hans. The Rise and Fall of Weimar Democracy. Chapel Hill e Londres: The University of North Carolina Press, 1996, esp. cap. 6. 
governaria a República até 1930, quando foi dissolvida pelo presidente.

Mas, talvez, o fenômeno que particulariza esta eleição foi a distribuição de mais de $20 \%$ de votos a um número grande de partidos que eram em geral contabilizados como sonstige ("outros"), nas estatísticas eleitorais. Partidos pequenos ou minúsculos, muitos dos quais eram os chamados "Partidos de Grupos de Interesse" (Interessenparteien), quase todos sem representação parlamentar anterior e cada um deles tendo obtido menos que $5 \%$ do total de votos, como o Partido Alemão-Hanoveriano, a Liga Eleitoral de Braunschweig, o Partido Camponês e o Partido da Classe Média Alemã (Reichspartei des deutschen Mittelstandes). ${ }^{20}$

Traço comum a quase todos estes partidos é o seu perfil claramente nacionalista, antissocialista e sua distância do campo republicano. Neste sentido, a fragmentação dos votos, sinal de problemas de legitimidade de partidos majoritários, foi acompanhada de um sinal adicional: a queda na legitimidade da república como projeto.

A república chega em princípios dos anos 30, assim, deslegitimada socialmente. E é no início dos anos 30 que ela seria atingida em um de seus pilares fundamentais: o Parlamento. Isto porque um projeto gestado no âmbito da presidência da república e colocado em prática a partir de maio de 1929 teve o objetivo de "retirar poder do parlamento e excluir os social-democratas da política de forma a transformar a democracia parlamentar em um estado autoritário governado pela direita". ${ }^{21} \mathrm{E}$ estes movimentos contaram com a anuência de partidos e personalidades que davam formalmente sustentação ao governo da "Grande Coalizão".

O presidente depõe o primeiro-ministro do SPD e coloca em seu lugar o conservador Heinrich Brünig (Zentrum). Este foi o momento em que, progressivamente, os decretos presidenciais (Artigo 48) tenderam a substituir o parlamento na atividade legislativa, solapando aos poucos o sistema político democrático-liberal da república e estabelecendo aquilo que fico conhecido como Gabinetes Presidenciais (Presidialkabinette), uma forma de exercício do poder fundado no autoritarismo das decisões monocráticas do presidente antirrepublicano Paul von Hindenburg. Este procedimento expandiu, contrariando o espírito da constituição, os poderes da presidência em detrimento do parlamento. Isto levou historiadores a dizer que, com a normalização dos gabinetes presidenciais, a república de Weimar começou a se dissolver.

É também neste tempo de estabilidade que se amplia o espaço do nacionalismo exclusivista e o vigor público e a capacidade de disseminação de ideias e de valores de organizações de extrema direita, dentre os quais o NSDAP.

É justamente neste tempo de estabilidade que o partido altera de forma decisiva sua forma de se organizar e de se apresentar publicamente, produzindo impacto em eleições regionais neste

\footnotetext{
${ }^{20}$ Os resultados detalhados das eleições ao longo da República estão disponíveis em: <www.wahlen-indeutschland.de>. Acesso em: 25 nov. 2017. Sobre o perfil dos Interessenparteien, cf.: CHILDERS, Thomas. The Nazi voter: The Social foundations of Fascism in Germany, 1919-1933. Chapel Hill: The University of North Carolina Press, 1983, p. 42-43.

${ }^{21}$ KOLB, Eberhadt. The Weimar Republic. New York: Routledge, 2004, p. 116.
} 
período, mas, acima de tudo, em 1930.

\section{O NSDAP na República de Weimar: do golpismo ao gigantismo}

O Partido Nazista é fundado em 1919 em Munique, Capital da Baviera, como Deutsche Arbeitpartei e muda de nome em 1921, quando passa a se chamar Nationalsozialistische Deutsche Arbeiterpartei (NSDAP). Hitler, que se aproxima do partido ainda em 1919, se projeta como propagandista em função de sua capacidade de oratória e isto lhe dá destaque no partido e no campo da extrema direita em Munique. Até novembro de 1923, quando ganha projeção nacional por conta de uma tentativa frustrada de golpe de Estado, Hitler e o NSDAP se movimentam no interior do campo político Völkisch mais amplo, do qual Erich Ludendorff, general e membro de destaque do último Comando Supremo do Exército durante a Primeira Guerra Mundial, é a figura de maior proeminência.

Conhecido como o "Golpe da Cervejaria" foi uma tentativa de derrubar o governo da república levada a cabo pela Associação Kampfbund (literalmente "Liga de Combate"), como era conhecida a Arbeitsgemeinschaft der Vaterländischen Kampfverbände, (Grupo de Trabalho das Associações Patrióticas de Combate), uma organização "guarda-chuva" de grupos paramilitares e organizações völkisch, dentre as quais se destacava o partido nazista. ${ }^{22}$

O golpe, aproveitando uma reunião convocada pelo Governo bávaro na Bürgerbräukeller, uma das maiores cervejarias de Munique, teve início na noite de 8 de Novembro. Interrompendo teatralmente a reunião, Hitler declara depostos os governos de Munique e de Berlim. Sem o apoio esperado, na madrugada do dia 9, os golpistas organizam uma marcha com o objetivo de conquistar apoio da população e de algumas unidades militares. Porém, isolado, o movimento encerra-se, numa barricada da polícia no centro da cidade. O tiroteio deixa um saldo de 14 golpistas e três policiais mortos e com a prisão da maioria das lideranças.

A prisão e o julgamento de Hitler o projetam como figura nacional com uma intensidade

inédita. Apesar de haver cometido o crime de alta-traição, uma corte altamente leniente o condena a somente nove meses de prisão na fortaleza de Landsberg, tendo cumprido somente seis antes de ser colocado em liberdade condicional.

No momento em que foi proibido, o partido conta com um jornal nacional (o Völkischer Beobachter - "O Observador Völkisch") e um pouco mais de 55.000 membros, organizados de forma fluida em aproximadamente uma centena de "organizações afiliadas" fora de Munique, mas que eram pouco controladas pelo comitê executivo do partido. ${ }^{23}$

${ }^{22}$ Sobre o Golpe, cf.: EVANS, Richard. A Chegada do Terceiro Reich. São Paulo: Planeta, 2010, p. 230 ss.

${ }^{23}$ No interior deste campo político Völkisch não é incomum que os partidos sejam bastante regionalizados, muitas vezes fortes e bem organizados em uma só cidade, e que recebam a filiação de organizações, 
Depois da tentativa frustrada de golpe, o jornal do partido é proibido, boa parte de seus membros são absorvidos por outras organizações do movimento Völkisch e o "centro" em Munique perde, em alguns casos, parcial, em outros totalmente, o pouco do contato que conseguia ter com os grupos organizados em torno do agora ilegal NSDAP.

A secundarização da construção de uma estrutura formal de partido está profundamente relacionada com as dimensões de seu projeto estratégico perseguido até esse momento. Tal como boa parte do movimento Völkisch, o NSDAP definia como seu objetivo final a derrubada da República de Weimar. Não é, portanto, sem razão que Hitler rejeita a participação do partido em quaisquer disputas eleitorais e opta pelo caminho do golpe político-militar.

Em 1925, logo após ter sido "re-legalizado", o partido conta com aproximadamente 20.000 membros e passa por uma grande reformulação da estrutura organizativa. Um duplo aspecto envolve esta questão. Por um lado, a tática golpista que levara ao Putsch de Munique é reavaliada e por outro há uma definição mais precisa tanto do projeto estratégico quanto do papel da estrutura partidária na consecução desse projeto.

Ao longo de 1924, algumas das alterações nas diretrizes políticas do partido já vinham sendo elaboradas por Hitler. "Quando eu retomar minhas atividades", ele teria declarado ainda na prisão a Kurt Ludecke, comerciante ligado ao Partido, "será necessário perseguir uma nova política. No lugar de buscar conquistar o poder por meio de uma conspiração armada, deveremos nos concentrar em entrar no Reichstag contra os católicos e os marxistas. Se ganhar deles no voto não leva mais tempo do que ganhar deles na bala, pelo menos os resultados vão ser garantidos por sua própria constituição". ${ }^{24}$ A "Revolução Legal" foi como o partido denominou esta nova estratégia.

Quando sai de Landsberg, Hitler e sua "facção" propõem condicionantes para a reorganização do partido. Estas condições dizem respeito ao controle da direção partidária por este grupo. Desta forma, o que se observa é a verticalização e a monolitização do partido em torno de Hitler, com o seu centro dirigente, a partir daí, desarticulando as facções pelo princípio da "submissão ou exclusão".

A autoridade de Hitler no partido por meios administrativos se fez acompanhar da opção consciente de afirmá-la simbolicamente por meio do "culto ao Führer". A saudação nazista, talvez a forma mais imediatamente visível da idolatria a Hitler, foi tornada compulsória em 1926 e foi acompanhada da institucionalização da construção de Hitler como uma "liderança heróica". ${ }^{25}$

também regionais e locais, que Ihes sirvam de "correias de transmissão" em lugares que, de outro modo, não poderiam ser alcançados por sua propaganda ou por sua organização. Para uma história do NSDAP até o Golpe de 1923, cf.: MASER, Werner. Der Sturm auf die... Op. cit.,. Para uma discussão sobre a composição social e as dimensões do partido e sua composição social até este momento, cf.: KATER, Michael H. Zur Soziographie der frühen NSDAP. In. Vierteljahrshefte für Zeitgeschichte. Nr. 19, 1971(2), p. 124ss.

${ }^{24}$ NOAKES, Jeremy \& PRIDHAM, Geoffrey. Nazism 1919-1945: A Documentary Reader. Exeter: University of Exeter Press, 1991, vol. I, p. 37.

${ }^{25}$ Sobre este processo, cf.: KERSHAW, Ian. Hitler. São Paulo: Companhia das Letras, 2010, cap. 7: Domínio 
A partir de 1926, a opção pela chamada "Revolução Legal" deu nova importância à participação em processos eleitorais locais, regionais e nacionais, que passou a direcionar a reorganização bem como todas as atividades partidárias. ${ }^{26}$

Com este propósito, o partido, sob o comando do secretário nacional de organização, Gregor Strasser, redesenha sua estrutura organizativa (chamada simplesmente de Organização Política - P.O.), redefine a sua distribuição regional de forma a adaptar as suas Gaue (regiões administrativas do partido) às vinte seis grandes regiões eleitorais da Alemanha, cada uma das quais dirigidas por um Gauleiter (chefe regional). Subordinados às Gaue estavam os círculos (Kreis), que correspondem a grupos organizados em cidades ou distritos (maiores ou menores), dirigidos por um Kreisleiter, chefe distrital. Abaixo dos Kreise encontram-se os Orstgruppen, grupos locais, dirigidos por um Orstgruppenleiter. O espaço de ação dos grupos locais foi definido como aquele de uma comunidade com algo em torno de 1500 famílias.

Diretamente subordinados aos Orstgruppen estavam as organizações de base propriamente ditas: as Zellen (células) responsáveis por uma área que incluía entre 160 e 480 famílias; e o Block, submetido às Zellen e responsável por uma área que consistia de 40 a 60 grupos familiares.

A outra mudança decisiva na estrutura partidária dizia respeito a seus departamentos como finanças, propaganda etc. A organização da propaganda partidária dá um exemplo importante dessas transformações.

Até a proibição das atividades do partido em 1923, a propaganda política resumia-se quase que exclusivamente aos comícios e à atividade militante da SA. Existiam responsáveis nas regiões (Gaue), mas que eram subordinados às direções regionais, o que faz com que o controle central das atividades locais seja bastante precário ou inexistente, visto que as próprias divisões internas e as lutas pelo controle do aparelho enfraquecem esta pretensa homogeneidade e centralização.

A partir de 1925, após iniciado o processo de "reconstrução", a estrutura da propaganda partidária ganha novos contornos. O controle da propaganda segue a lógica da centralização do partido em torno de Hitler e de seu "grupo". Enquanto a estrutura local era ainda a responsável pela seleção e formação de seus "oradores" e pela forma como eram conduzidas campanhas eleitorais ou pela organização da imprensa partidária, as variações de abordagem das "grandes questões" tendem a deixar de existir com a diluição das divisões internas.

Com a redefinição tática e estrutural do partido, o NSDAP passa a contar com um departamento responsável somente pela propaganda partidária. Esta passa a ser absolutamente verticalizada e "paralela" à própria estrutura formal do partido: todas as instâncias partidárias passam a ter um responsável pela propaganda, submetido diretamente ao seu superior

do Movimento, especialmente p. 217ss.

${ }^{26}$ Sobre as mudanças na organização partidária, cf.: BRACHER, Karl Dietrich. Die Deutsche Diktatur. Berlin. Ullstein, 1997, cap. 3; e, EVANS, Richard. A Chegada do Terceiro... Op. cit., p. 265-275. 
departamental. Duas prioridades quanto à organização do trabalho de propaganda são definidas: recrutar "formadores de opinião" em todas as categorias ou segmentos correspondentes aos "departamentos" e "formar quadros" de maneira centralizada objetivando não só a capacitação para as atividades de propaganda propriamente ditas bem como a própria preparação de quadros para assumir funções dirigentes no partido ou no estado. ${ }^{27}$ Além disso, definiu-se uma estrutura interna de assessoria aos "oradores" enviados a cada região cujo papel era amparar a atividade com o máximo de informação possível sobre política e economia locais etc. Inicialmente Heinrich Himmler e, a partir de 1929, Joseph Goebbels dirigiram a secretaria nacional de propaganda e passaram a controlar todos os aspectos da atividade de propaganda do partido, incluindo parte importante de seus rituais. ${ }^{28}$

Além disso, na segunda metade da década de 20, ao lado da Organização Política (P.O.), são constituídas organizações capilares como a Juventude Hitlerista (Hitlerjugend - HJ), a Organização Nacional Socialista de Mulheres (Nationalsozialistische Frauenschaft - NSF) e organizações por ramo de atividades como a dos estudantes universitários, de professores escolares, de advogados, de operários fabris, agricultores etc., que, podiam ser representadas em todas as instâncias do partido, dos núcleos até o topo. A partir de 1928 verifica-se, progressivamente, uma mudança operacional destas organizações: estes departamentos tornamse também verticalizados e "paralelos" à Organização Política (P.O.). Esta alteração objetivava intensificar o trabalho de propaganda militante junto aos segmentos correspondentes em função de suas especificidades.

Com este amplo processo de reestruturação, pereniza-se o trabalho organizativo e propagandístico do partido fazendo com que ainda no final da década de vinte o NSDAP ganhe proporções de um partido de massas voltado para a conquista de espaços institucionais na política alemã. O crescimento anual das tiragens médias do jornal Völkischer Beobachter dão um sinal deste crescimento: de 1926 a 1927 o crescimento foi de pouco mais de 26\%, de 1927 para 1928 de pouco mais de $21 \%$, de 1928 a 1929 foi de em torno de 60\% e de 1929 para 1930 de pouco mais de 200\%. A partir daí o crescimento das vendas cai proporcionalmente e entre 1930 e 1931 chega a $28 \%$ e de 1931 a 1932 foi pouco mais de $16 \%$.

O crescimento do número de membros do partido também é um bom índice da ampliação da influência do partido nos anos acompanha esta tendência.

Tendo em torno de 27.000 membros em 1925, o partido encerra o ano de 1928 contando 100.000 membros. Um ano depois já contabiliza 178.000 e em março de 1930 já são 210.000. No

27 Nesta época, o partido passou a contar com cursos de treinamento mais ágeis "enviados" às diversas regiões, outros por correspondência, e foi construída uma escola do NSDAP para oradores, estabelecida em 1929.

28 Sobre a propaganda, cf.: BRACHER, Karl Dietrich. Die Deutsche Diktatur. Op. cit, p. 214ss; e, OHR, Dieter. NS Propaganda und Weimarer Wahlen: Empirische Analysen zur Wirkung von NSDAP-Versammlungen. Wiesbaden: Springer Fachmedien, 1997. 
final de 1932 os membros do partido somavam cerca de 1.000.000. ${ }^{29}$

Paralelamente, o partido, em sua apresentação pública, ameniza seu ímpeto anticapitalista para tornar-se palatável a setores mais amplos do eleitorado. Contudo, ele é ainda tomado como um partido inexpressivo em função de sua representação no Reichstag: somente 2,8\% de votos obtidos nas eleições de 1928. Porém, estes ajustes de rota bem como seu processo de reestruturação mostraram seus primeiros frutos em eleições regionais em 1929, com índices de crescimento surpreendentes: na Saxônia: de 1,6 (10/1926) para 5\% (05/1929); em Baden: de 1,2 (10/1925) para 7\% (10/1929); em Berlin: de 1,5 (10/1925) para 5,8\% (12/1929) e na Turíngia: de 3,5\% (01/1927) para 11,8\% (10/1929). As eleições na Turíngia levaram o partido a, pela primeira vez, compor uma coalizão governamental. Wilhelm Frick passou a ocupar a pasta do Interior e da Educação. Todos estes avanços foram sentidos antes mesmo que os efeitos da crise que teve início com a quebra da bolsa de Nova York fossem sentidos de forma plena na Alemanha. ${ }^{30}$

\section{Os nazistas tornam-se alternativa}

Ainda no ano de 1929, duas oportunidades oferecidas pela conjuntura permitiram ao NSDAP ampliar sua exposição pública e alterar a sua posição: por um lado, a ampliação dos vínculos do NSDAP com os conservadores e, por outro, a conjuntura de crise econômica mundial.

A primeira oportunidade foi aberta pela adoção pela Alemanha do Plano Young em junho de 1929. Trata-se de um novo acordo sobre o pagamento das reparações previstas pelo Tratado de Versailles, resultado do esforço do Ministro das Relações Exteriores Gustav Stresemann para rever as condições de pagamento de reparações estabelecidas pelo Plano Dawes. ${ }^{31}$

O plano abre para a oposição de direita e de extrema esquerda, a possibilidade, mais uma vez, para desgastar a república por meio do Tratado de Versailles. As reações a este segundo plano começaram tímidas, tendo a frente o KPD e o DNVP. Mas, para os nazistas, a luta contra o plano traz benefícios de longo alcance. Graças ao novo líder antirrepublicano dos nacionalalemães, Alfred Hugenberg, os nazistas são "convidados" a cooperar com uma campanha nacional contra o plano, que reuniria o nacionalismo ultraconservador, monarquistas e figuras proeminentes da burguesia industrial.

Esta campanha coincidiu com a depressão econômica mundial advinda da quebra da bolsa

\footnotetext{
${ }^{29}$ Ibidem, p. 229-239.

30 Dados extraídos de: FEUCHTWANGER, E. J. From Weimar to Hitler... Op. cit., p. 215.

31 O Plano Young dizia respeito, basicamente, à reprogramação dos pagamentos (redução das anuidades) e a um empréstimo a ser feito à Alemanha. O peso do plano se encontra, porém no fato de haver confirmado o artigo 231 de Versailles (que tratava da culpa da Alemanha pela guerra) e de a renegociação projetar os pagamentos até 1988. Sobre a renegociação dos pagamentos e o plano Young, cf.: MOMMSEN, Hans. The Rise and Fall... Op. cit., p. 288-275.
} 
de valores de Nova York, que em pouco tempo produz efeitos devastadores na Alemanha. Porém, tão importante quanto a coincidência com a crise, foi a coincidência com os processos eleitorais regionais. Com a chance inédita de contar com os fundos e o espaço de propaganda fornecido pelo império de Hugenberg (que incluía inúmeros jornais diários por toda a Alemanha), os nazistas aproveitaram de imediato a oportunidade, demandando, porém, completa independência propagandística e uma "boa parte dos fundos ofertados". Além disso, a campanha contra o Plano Young e a aproximação com os nacional-alemães representou, para os nazistas, a saída de um gueto político relativamente estreito do campo völkisch e a possibilidade de atingir setores médios e de elite até então receosos da radicalidade do partido.

Ao lado disso, a crise aberta pela quebra da bolsa de Nova York em 1929 atinge a Alemanha entre fins de 1929 e princípios de 1930. A crise representou para a Alemanha não somente a interrupção abrupta da entrada, mas também a retirada dos capitais que possibilitaram a relativa estabilidade econômica do país. Com ela vieram uma recessão econômica aguda e uma crise social sem paralelo.

Até setembro de 1930 o número de desempregados saltou de 1,3 para 3 milhões. Um ano mais tarde eram 5,1 milhões e em princípios de 1933 a fronteira dos seis milhões de desempregados foi ultrapassada.

Ao lado disso, aquela que é a instituição por excelência do parlamentarismo democráticoliberal começou a ser desmontada por uma ação iniciada em meados de 1929 pela presidência da república, mas levada a efeito em comum acordo com um parlamento cada vez mais conservador.

O propósito seria o de isolar a social-democracia e construir uma alternativa autoritária para a Alemanha, dissolvendo, por meio de uma aliança de partidos e grupos conservadores, as instituições do sistema político de Weimar. Os golpes sequenciais e decisivos contra as instituições republicanas foram corrosivos para o sistema de Weimar.

A partir de 1930, governos sucessivos dispensaram as maiorias parlamentares e, deformando os pilares da constituição, transformaram o sistema político em um sistema autoritário, cada vez mais marcadamente de direita. Os governos de minoria se ancoravam nos decretos presidenciais permitidos pelo artigo 48 para situações de emergência e de risco das instituições. Com os primeiros-ministros conservadores Heinrich Brüning (março de 1930 a maio de 1932), Franz von Papen (junho a dezembro de 1932) e general Kurt von Schleicher (Dezembro de 1932 e Janeiro de 1933), que não escondiam seus desejos de desativar o sistema parlamentar, este recurso serviu de instrumento para tirar, em termos práticos, o parlamento do jogo político.

No quadro partidário, a conjuntura de crise e radicalização fez com que, até mesmo nos partidos que davam sustentação à república, tendências políticas mais conservadoras ou de direita saíssem vitoriosas, representando a retomada de uma linha política de enfrentamento radical com o projeto republicano.

O outro espaço de onde se evidencia a polarização política são as ruas. Ao mesmo tempo 
em que este momento vê um processo de ascensão de grupos e partidos da extrema esquerda e da extrema direita, as milícias partidárias ganham um novo ímpeto, em suas disputas por espaço e em seus confrontos geravam um clima de agitação e caos social.

A conjuntura marcada pelo clima de crise social e de rearranjos na paisagem políticopartidária e a ajuda de Hugenberg em projetar publicamente o partido, foram bem aproveitadas pelo NSDAP no sentido de confirmar a tendência de crescimento eleitoral. As eleições de setembro de 1930, de fato, representam uma ruptura histórica para o partido nazista e um abalo profundo no movimento eleitoral relativamente estável da Alemanha. Em dois anos o NSDAP saiu de 2,8\% para $18,3 \%$ de votos para o parlamento nacional, o que representou em termos absolutos sair de 812 mil para 6,4 milhões de votos.

Com isto o partido não somente ganha projeção inédita no cenário político alemão como também reforça a tendência do conservadorismo antirrepublicano de se aproximarem do partido. E a aproximação com o DNVP de Hugenberg se transforma em condição de possibilidade para o NSDAP se tornar mais palatável para a elite alemã. Isto ganha materialidade prática em 1931 com a constituição da Frente de Harzburg, que foi formada pelo esforço de Hugenberg de reunir a chamada "oposição nacional" (ultraconservadora) em um bloco político. O bloco se concretiza em um grande comício na cidade de Bad Harzburg, no qual estiveram presentes membros de setores distintos das elites alemães: agraristas, industriais, militares, aristocratas, e lideranças pangermanistas. A frente teve curta duração, mas representou a ampliação dos contatos do partido nazista com as elites alemãs e possibilidades até então inéditas de financiamento.

A combinação de crescimento eleitoral e de número de membros do partido e de estreitamento das relações com parte da elite alemã torna o nacional socialismo desejado por setores conservadores antirrepublicanos, que dominavam a cena política desse momento.

A candidatura de Hitler á presidência da república, na qual conquista nos dois turnos 30,1 e 36,8 dos votos (março e abril de 1932) e o desempenho do partido nas eleições de julho de 1932, quando conquistou $37,3 \%$ dos votos, transformam-no em uma aposta da direita alemã para uma coalizão de direita que buscaria solucionar a crise política na qual a Alemanha havia mergulhado.

Na primeira tentativa, Hindenburg se recusa a aceitar a exigência de Hitler para compor um governo: ser Primeiro-Ministro. Depois desta recusa dos nazistas, registra-se o primeiro e mais grave revés eleitoral do partido. Nas novas eleições para o Reichstag em novembro, o NSDAP perde algo em torno de dois milhões de votos, reduzindo sua participação a $33,1 \%$ e, como saldo, experimenta também uma crise interna.

Em seu diário, Joseph Goebbels, líder proeminente do partido, registra o abatimento que parece ter tomado conta do partido após as eleições de novembro de 1932:

6.11 .1932 - "Nós tomamos uma pancada. [...]"

10.11.1932 - "Novamente em Berlim. O clima no partido, que no começo era muito positivo, degringolou em depressão. Por toda a parte só se vê aborrecimento, brigas e desentendimentos." 
24.12.1932 - O ano de 1932 foi uma eterna maré de azar. [...] Lá fora a paz do Natal está nas ruas. Estou sentado sozinho em casa, pensando sobre muitas coisas. O passado foi duro, e o futuro é escuro e opaco; todas as perspectivas e esperanças desapareceram por completo. ${ }^{32}$

Esta avaliação feita por Goebbels foi partilhada por muitos outros membros da própria direção do Partido Nazista. E de fato a situação do partido era, hoje sabemos, muito delicada. Ao lado de dívidas, a queda nas assinaturas do jornal Völkischer Beobachter, o desmoronamento de uma direção coesa, fator preponderante de sua intervenção no espaço público desde a reorganização, indicavam problemas à frente. Além disso, nas eleições regionais e locais na Turíngia, que tiveram lugar em Dezembro, o partido amargou perdas de mais de $40 \%$ dos votos obtidos nas últimas eleições para o parlamento nacional, o cenário parecia ser, de fato, sombrio. ${ }^{33}$

O crescimento do partido e os votos conquistados não só não eram vistos pelos contemporâneos como um sinal inequívoco de que a vitória política, representada pela nomeação de Hitler à chancelaria do Reich, estaria assegurada, mas muitos deles avaliaram que o melhor momento para os Nazistas havia passado.

Entre novembro de 1932 e janeiro de 1933, mesmo tendo recentemente nomeado Schleicher como primeiro-ministro de mais um gabinete presidencial, pressões vindas de grupos de interesse que insistiram com o presidente Hindenburg para que a Chancelaria fosse entregue a Hitler.

A primeira petição foi enviada ainda em novembro por um grupo pouco representativo de banqueiros, industriais, ainda que com apoio firme dos grandes proprietários de terras. A ela se seguiu outra que, em janeiro, ampliou um pouco o número de signatários, ainda que sem incorporar representantes de associações da grande indústria.

A aposta, articulada pelo ex-primeiro-ministro Franz von Papen era de que os nazistas formassem uma coalizão com outros partidos de direita. A expectativa era de que, com seu suporte de massas, seria possível formar um gabinete presidencial que, definitivamente, pudesse realizar o projeto substituir a república liberal-democrática por um regime autoritário, ainda que diferente daquele pretendido e realizado posteriormente pelos nazistas.

De fato, mesmo considerando a capacidade de mobilização do NSDAP e seu surpreendente crescimento eleitoral, Hitler e o NSDAP foram "salvos" devido a um jogo de pressões feitas ao presidente Hindenburg por representantes das antigas elites.

As pressões passam a ser exercidas diretamente por von Papen, por Otto Meissner, secretário de Estado e conselheiro próximo de Hindenburg, e por Otto von Hindenbrg, filho do presidente. Eles finalmente convencem o relutante von Hindenburg a convidar, em 30 de janeiro de 1933, Hitler para ocupar o posto de primeiro-ministro da república a compor um novo governo.

${ }^{32}$ REUTH, Ralf Georg (ed.). Joseph Goebbels Tagebücher. München: Piper, 1999, vol. 2, p. 714, 717, 740.

33 Cf.: FLECHTHEIM, Ossip K. Die KPD in... Op. cit., p. 225-227. Sobre a crise no partido derivada desta conjuntura, cf.: MOMMSEN, Hans. The Rise and Fall... Op. cit., p. 504 ss. 
Este último governo da República de Weimar foi composto somente por antirrepublicanos convictos e militantes. Seis meses depois, todas as instituições republicanas, partidos políticos e associações da sociedade civil estavam destruídas. ${ }^{34}$

\section{Considerações finais}

Ao longo da história dos estudos sobre o fim da primeira experiência republicana na Alemanha e de sua sucessão pela ditadura nazista, progressivamente se assenta a percepção de que este fenômeno resiste a explicações monocausais.

Para a chegada de Hitler ao cargo de primeiro-ministro em Janeiro de 1933, concorreram variáveis muito diversas em sua eficácia. Quatro delas, que foram indicadas ao longo do artigo, me parecem incontornáveis: a progressiva perda de legitimidade do projeto republicano democrático-liberal, tanto em função de desgastes diversos verificados ao longo dos anos 20 quanto dos ataques constantes de seus inimigos; a aguda crise econômica e social de princípios dos anos de 1930 que encontra uma configuração social e um ambiente político e cultural propenso (ou pelo menos, que não se opunham) a soluções autoritárias; as iniciativas do próprio partido nazista, que se reestruturou para conquistar legitimidade pública; e, o apoio das elites alemãs (e suas pressões neste sentido junto a Hindenburg) para que aos nazistas fosse "dada uma chance".

Uma república com uma imagem fragilizada por um longo processo de desgaste político e por uma conjuntura de crise econômica e social aguda termina nas mãos de grupos e de indivíduos que não têm interesse em defendê-la.

A República de Weimar enfrentou crises conjunturais que, isoladamente, são momentos de instabilidade aguda, mas que, se tomadas em conjunto, foram momentos do enfraquecimento progressivo das forças políticas que davam sustentação ao projeto republicano democráticoliberal, implantado como nova forma de ordenamento social, jurídico e político para a Alemanha pós-imperial. E para isto contribuíram de forma decisiva o desgaste que a república sofreu tanto da esquerda quanto da direita, para quem a constituição de Weimar era um inimigo comum.

Mas a deslegitimação social da república e a derrota do projeto weimariano não necessariamente levariam os nazistas ao poder. A afirmação do partido como alternativa de poder na Alemanha ao longo da segunda metade dos anos 20 é outra variável decisiva neste complexo desenvolvimento.

Com um programa político e com palavras de ordem socialmente disseminados pela direita e já amplamente difundidos no momento em que o NSDAP ocupa o espaço público, o partido, em

${ }^{34}$ A respeito deste processo, cf.: BRACHER, Karl Dietrich. Die Deutsche Diktatur. Op. cit., cap. 4 e 5; e, MOMMSEN, Hans. The Rise and Fall... Op. cit., p. 504ss. 
torno da liderança carismática de Hitler, se afirma no espaço público alemão por suas opções de construção. Estas opções, ligadas a sua estratégia de enfrentamento com a república, dão a ele instrumentos políticos e organizativos que o destacavam do restante da extrema direita völkisch e dos partidos de direita tradicionais.

Contudo, a sedução das massas e a conquista bem-sucedida de votos ainda é insuficiente para dar conta do "30 de Janeiro de 1933", que se dá exatamente dois meses depois de o NSDAP ter visto seu crescimento eleitoral interrompido com uma perda de votos significativa e que foi considerada, então, como derrota decisiva.

As opções e avaliações políticas dos atores em jogo, que imaginaram poder usar "as massas" de Hitler como fator de estabilidade política, controlando os ímpetos radicais do líder nazista em direção a um regime autoritário, foram também decisivas. Aqueles que intervieram no conturbado cenário dos últimos meses de 1932 e princípios de 1933 para derrotar definitivamente o projeto weimariano apoiando-se no sucesso dos nazistas foram componentes vitais para que um líder de um partido radical de massas se tornasse um líder de um governo controlado pelos conservadores.

Todas estas variáveis são colocadas em movimento pela percepção de que, ainda que se combinem em uma mesma conjuntura, estamos lidando com fenômenos que devem ser considerados, em termos analíticos, separadamente: os elementos que permitem entender a fragilização do projeto republicano democrático-liberal na Alemanha do pós-guerra, o processo de construção e de afirmação do partido nazista no espaço público alemão e as variáveis da conjuntura que fizeram com que ele fosse considerado por muitos, naquele momento, uma alternativa de poder na Alemanha. Eles se entrecruzam em um momento em que a crise teve papel destacado em provocar expectativas de mudança e uma busca por soluções radicais por parte do eleitorado. Contudo não é possível desconsiderar nem a configuração específica da sociedade alemã do pós-guerra e a sua sensibilidade para acolher uma ou outra opção política apresentada (em grande medida, o resultado de uma conformação de mais longo prazo) e nem o fato de que forças políticas diversas se movimentaram nesta conjuntura, fazendo uso distinto dos recursos políticos e sociais de que dispunham. Neste sentido, agentes sociais, individuais e coletivos, fazendo escolhas de que caminho seguir e de como interagir com os elementos da conjuntura, tiveram também papel destacado, consciente ou inconscientemente, para produzir o fim da primeira experiência republicana na Alemanha e para que os nazistas tivessem chegado ao poder.

Luís Edmundo de Souza Moraes: Professor Associado de História Contemporânea do Departamento de História e do Programa de Pós-Graduação em História da Universidade Federal Rural do Rio de Janeiro (UFRRJ). Graduado em História pela Universidade Federal do Rio de 
Janeiro (UFRJ), mestre em Antropologia Social pelo Museu Nacional da UFRJ e Doutor em História pelo Centro de Pesquisas Sobre o Antissemitismo da Technische Universität Berlin. Coordenador do Núcleo de Estudos da Política da UFRRJ (NUEP-UFRRJ). 